\title{
EMPREENDEDORISMO RURAL: UM ESTUDO BIBLIOMÉTRICO
}

\author{
ROCHA, Geneci da Silva Ribeiro ${ }^{1}$ \\ ROCHA, Patricio Duarte ${ }^{2}$ \\ OLIVEIRA, Letícia de ${ }^{3}$
}

ISSUE DOI: $10.3738 / 1982.2278 .3558$

\begin{abstract}
RESUMO: O interesse por pesquisas acadêmicas sobre empreendedorismo rural tem-se intensificado nos últimos anos, principalmente nos países europeus. Neste sentido, o estudo teve como objetivo analisar a evolução da produção cientifica sobre empreendedorismo rural durante o período de 2010 a 2017. A pesquisa foi desenvolvida por meio de um estudo bibliométrico na base de dados Elsevir Scopus, conduzida pela metodologia Prisma. Por meio da aplicação dessa metodologia, foram selecionados 50 artigos para análise deste estudo. Tendo como critério análises da evolução cronológica dos artigos, principais áreas do conhecimento que publicaram sobre Empreendedorismo Rural, números de publicações por Países e instituições que publicaram sobre empreendedorismo rural. A partir da análise, os resultados apontaram que entre 2010 e 2011 os números de publicações mantiveram-se inalterados, já em 2012 obteve uma redução significativa. Todavia, evoluiu em meados do ano de 2012 para 2014 , ocorrendo novamente um declínio em 2014 para 2015, entre 2015 e 2016 houve um sobressalto nas publicações; por fim, no ano de 2017 manteve o mesmo índice de publicações. A maior parte das publicações concentra-se no Reino Unido e Estados Unidos. Em relação as áreas temáticas as que sobressaíram foram Negócios, Gestão e Contabilidade, seguida das áreas das Ciências Sociais. Na análise sistemática identificou-se as principais abordagens teóricas como comportamento empreendedor, competências e diversificação. A metodologia mais utilizada foi o estudo de caso, estudos qualitativos e quantitativos, e nos resultados e conclusões apontados nos artigos analisou-se os traços de personalidade, concluindo que a falta compreensão sobre o processo empreendedor está afetando o comportamento empreendedor dos trabalhadores rurais. Os autores concluem que os proprietários demonstram diferentes competências, como: interesse, vontade, habilidades, disposição e conhecimento para o desenvolvimento da economia local. Conclui-se que a descoberta de oportunidades desempenha papéis importantes que contribuem para a criação dos novos empreendedores rurais.
\end{abstract}

Palavras-chaves: Empreendedor rural. Produção cientifica. Bibliometria

\section{RURAL ENTREPRENEURSHIP: A SCIENTIFIC STUDY}

\begin{abstract}
SUMMARY: Interest in academic research on rural entrepreneurship has intensified in recent years, especially in European countries. In this sense, the study aimed to analyze the evolution of scientific production on rural entrepreneurship during the period from 2010 to 2017. The research was developed through a bibliometric study in the Elsevir Scopus database, conducted by the Prisma methodology. Through the application of this methodology, 50 articles were selected for analysis of this study. Based on analyzes of the chronological evolution of the articles, main areas of knowledge they published about Rural Entrepreneurship, numbers of publications by Countries and institutions that published on rural entrepreneurship. From the analysis, the results pointed out that between 2010 and 2011, the numbers of publications remained unchanged, already in 2012 obtained a significant reduction. However, it evolved in the middle of the year 2012 to 2014, once again a decline in 2014 to 2015, between 2015 and 2016 there was a start in the publications; Finally, in 2017, it maintained the same index of publications. Most publications focus on the United Kingdom and the United States. Regarding the thematic areas, those that stood out were Business, Management and Accounting, followed by the areas of Social Sciences. In the systematic analysis the main theoretical approaches were identified as entrepreneurial behavior, competences and diversification. The most used methodology was the case study, qualitative and quantitative studies, and the results and conclusions pointed out in the articles analyzed the personality traits, concluding that lack understanding about the entrepreneurial process is affecting the entrepreneurial behavior of rural workers. The authors conclude that the owners demonstrate different

\footnotetext{
${ }^{1}$ Administradora, Especialista em Gestão Pública, Mestranda no Programa de Pós Graduação em Agronegócios Universidade Federal do Rio Grande do Sul.

${ }^{2}$ Técnico em Agropecuária, Matemático - Universidade Federal de Pelotas

${ }^{3}$ Administradora, Docente no Departamento de Economia e Relações Internacionais e no Programa de Pós Graduação em Agronegócio na Universidade Federal do Rio Grande do Sul
} 
competences, such as: interest, willingness, skills, disposition and knowledge for the development of the local economy. It is concluded that the discovery of opportunities plays important roles that contribute to the creation of the new rural entrepreneurs.

Keywords: Rural entrepreneur. Scientific production. Bibliometria.

\section{INTRODUÇÃO}

A temática empreendedorismo passou a figurar-se mais proeminentemente na literatura, a partir do século XX onde recebeu uma maior atenção por parte dos pesquisadores devido as mudanças e crises na sociedade rural. A vista disso entendeu-se que o empreendedorismo poderia contribuir para o desenvolvimento rural e econômico (TOMEI; SOUSA, 2014). O empreendedorismo é visto como estabelecimento de novos negócios e tem uma influência positiva na economia de um país com geração de renda e trabalho no meio rural. (CHUN; WATANABE, 2012).

De acordo com Souza et al. (2013), o termo empreendedorismo foi empregado por Joseph Schumpeter nos anos 1950, o qual afirma que o empreendedor é uma pessoa dotada de criatividade e capaz de fazer sucesso em função do seu espirito inovador, transformando-se em um agente eficaz de mudança para a economia. Combinações como estas podem tomar novas formas pelo desenvolvimento de formatos de produtos, de métodos de produção, o desenvolvimento de fontes de fornecimento, identificação de mercados e no aproveitamento de determinadas inovações da organização da indústria (PATO; TEIXEIRA, 2016).

Tem-se discutido muito a respeito das habilidades empreendedoras e suas características. Souto et al. (2015), afirmam que empreender consiste no prazer de realizar com sinergismo e inovação algum projeto pessoal ou organizacional, em desafio permanente às oportunidades e riscos. Para Young(2010), os empreendedores que começam um negócio para prover renda e flexibilidade para suas famílias têm alcançado o sucesso mais rápido do que aqueles motivados por um desejo de grande riqueza e de desafiar a si mesmo.

Segundo Muhammad et al. (2017), o empreendedorismo em mercados emergentes, principalmente, em áreas rurais de países em desenvolvimento é diferenciado daquele praticado nos países em desenvolvimento. De acordo com os mesmos autores o empreendedorismo é de fundamental importância para o desenvolvimento do setor rural nos países em desenvolvimento, de forma a aumentar a oportunidade de criar empregos, e consequentemente reduzir a pobreza. Empresas rurais fornecem muitos impactos sociais as comunidades locais onde estão inseridas, fornecendo não só produtos e serviços, mas também novas oportunidades de trabalho (ESCHKER; GOLD; LANI,2017).

De Los Rios et al. (2016), dizem que o empreendedorismo, atualmente, apresenta-se como uma oportunidade de trabalho, assim como um fator chave que influência positivamente a economia em que é visto como um processo de identificar, avaliar e explorar as oportunidades existentes.

Balraj e Velmurugan (2017), afirmam que o empreendedor rural opera como catalizador do desenvolvimento rural, aproveitando os recursos de maneira otimizada, oferecendo oportunidades de trabalho às pessoas das áreas rurais. Sendo assim o empreendedorismo rural funciona como mecanismo de controle da migração da população das zonas rurais para as zonas urbanas.

Para Veiga (2001), os estabelecimentos agrícolas nos quais núcleos familiares compõem um pequeno negócio, e na maioria das vezes informais são fartos de habilidades empreendedoras e estimuladores do empreendedorismo. Sendo estes, pequenos negócios comerciais, artesanais ou agroindústrias que mais diversificam a economia local. 
Os empreendimentos rurais apresentam-se em destaque na economia mundial. De acordo com Centro de Estudo Avançado em Economia Aplicada (CEPEA) da Escola Superior de Agricultura Luiz de Queiroz (ESLAQ/ USP), O Produto Interno Bruto (PIB) do agronegócio no Brasil em 2016 cresceu $4,48 \%$, em comparação com o desempenho do ano anterior. Atualmente, o empreendedorismo responde por $30 \%$ dos brasileiros envolvidos em algum tipo de negócio. Assim compete destacar a importância do papel do agronegócio, campo este gerenciado pelo empreendedor rural, nutrido como uma das fundamentais locomotivas da economia brasileira que estão sujeitas a regras de mercado, variação cambial, e variações climáticas (BRACHT; WERLANG, 2015).

O empreendedorismo rural desempenha um papel muito importante no desenvolvimento econômico de um país e é visto atualmente como um dos principais impulsionadores da economia, através geração de trabalho e renda, no aproveitamento da inovação, manutenção e no desenvolvimento de comunidades.

Portanto, o objetivo deste estudo é analisar a evolução da produção cientifica sobre empreendedorismo rural, a partir de 2010 a 2017 publicada na base de dados Elsevier Scopus.

\section{METODOLOGIA}

A pesquisa ocorreu com base nos artigos indexados na base de dados Elseveir Scopus nos mês de julho de 2018. Realizou-se à revisão bibliométrica com análise sistemática do conteúdo dos artigos, seguindo o protocolo Prisma. Segundo Araújo (2006), a revisão bibliométrica consiste no uso de técnicas estatísticas e matemáticas para características da literatura e de outros meios de comunicação. O protocolo Prisma procura auxiliar os pesquisadores a melhorarem o relato das revisões sistemáticas ou meta-análises.

Para Moher et al. (2015), a revisão sistemática, adotada pelo protocolo Prisma tem como base uma pergunta formulada objetiva, utilizando métodos sistemáticos e compreensíveis, comportando identificar, selecionar e avaliar de forma crítica as pesquisas mais relevantes sobre o assunto pesquisado. Dessa forma, a análise segue os seguintes procedimentos operacionais: A) Primeira etapa: Desde já, definiu-se a base de dados da pesquisa para a busca dos artigos, em que foi utilizada a Elsevir Scopus. Além disso, inseriu-se a palavra-chave, em idioma inglês, no mecanismo de busca: "rural entrepreneurship" (no título, resumo e palavra-chave), escolhendo o tipo de documento "artigo".

Ao determinar esse procedimento, encontram-se 88 artigos no mês de julho de 2018. Após, definido o mesmo, aplicou-se a metodologia do protocolo Prisma, conforme a Figura 1. 
Figura 1- Fluxograma de identificação e seleção dos artigos para a revisão bibliométrica sobre Empreendedorismo Rural.

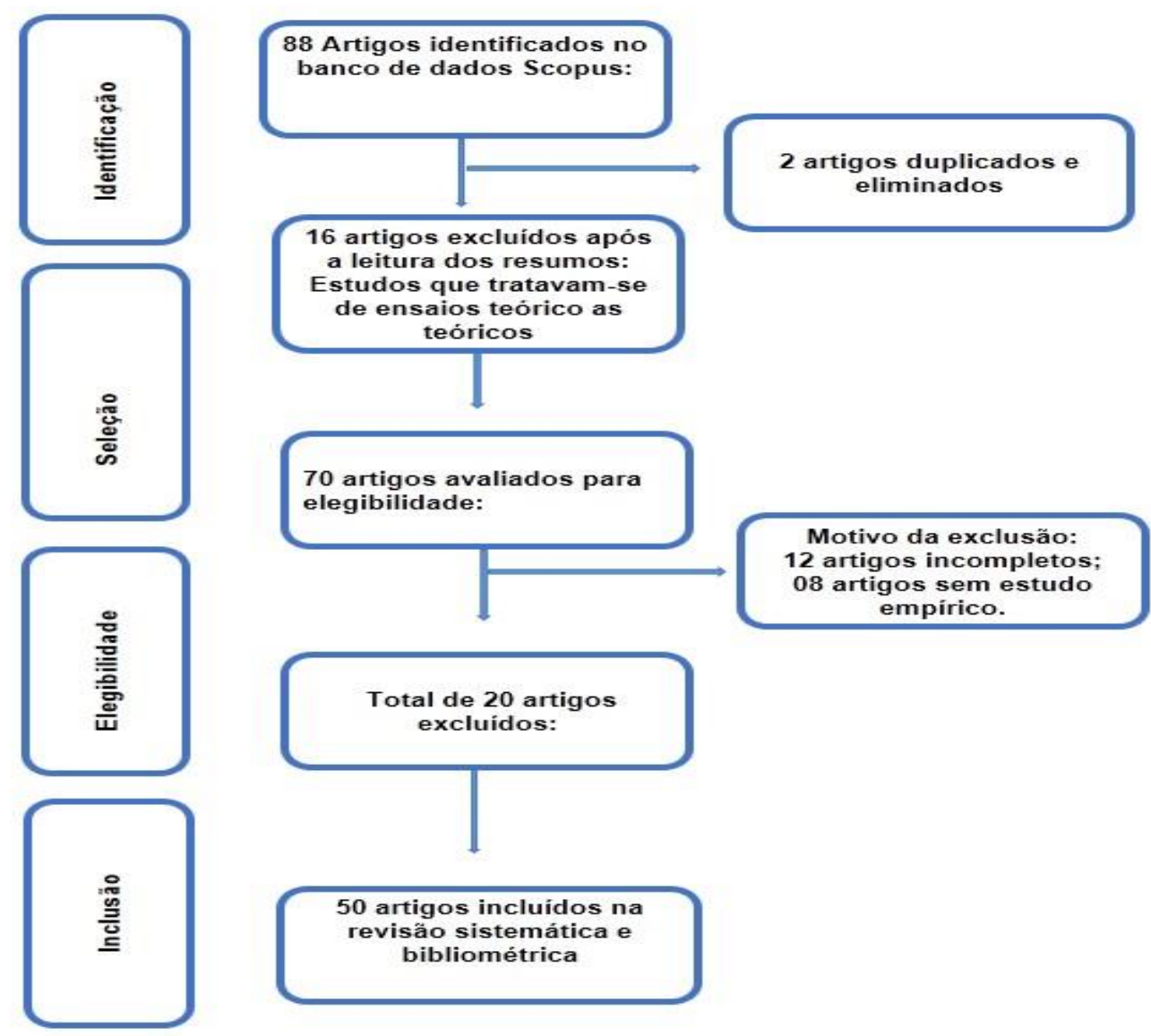

Fonte: Elaborado pelos autores com base no fluxograma Prisma.

Na figura 1, nota-se que dos 88 artigos da pesquisa apenas 50 atenderam às quatro etapas do fluxograma: identificação, seleção, elegibilidade e inclusão. A eliminação de 38 artigos refere-se àqueles que não disponibilizaram o seu texto completo na web, aqueles que tratavam-se de ensaios teóricos e também, aqueles que eram de idiomas diferentes do inglês.

B) Segunda etapa: definiu-se os principais indicadores bibliométricos e os principais assuntos da revisão sistemática: 1- principais indicadores bibliométricos: evoluções cronológicas dos artigos, áreas do conhecimento de publicação dos artigos, números de publicações por País; instituições que publicaram sobre empreendedorismo rural e 2 - Principais assuntos da revisão sistemática geral: principais abordagens teóricas, procedimentos metodológicos utilizados, perfil das amostras e os principais objetivos dos artigos analisados e seus resultados e conclusões.

A análise e discussão dos resultados foram desenvolvidas de acordo com as seguintes etapas: (a) Busca por documentos a partir das palavras-chaves "rural entrepreneurship"; (b) Delimitação para apenas publicações de artigos, sendo encontrados 50 documentos; (c)Análise quantitativa da evolução cronológica, áreas de estudos, países de publicação, instituições que mais publicam, (d)Análise qualitativa a partir de uma revisão sistemática dos artigos. 


\section{ANÁLISE E DISCUSSÃO DOS RESULTADOS}

Foram encontrados 88 artigos na pesquisa. No entanto, ao adotar o fluxograma da metodologia Prisma, selecionou-se 50 artigos para análise em que, inicialmente, foi estudada a evolução cronológica dos artigos, conforme a Figura 2.

Figura 2- Evolução cronológica dos artigos.



Fonte: Elaborado pelos autores (2018).

Partir do exposto na figura 2, percebe-se que as publicações de artigos referente ao Empreendedorismo Rural entre 2010 e 2011, mantiveram-se inalteradas, já em 2012 teve uma redução significativa para 3 publicações. Todavia, evoluiu no ano de 2012para 2014, de 3 publicações para 7 artigos publicados, tendo uma queda novamente de 2014 a2015 para 6 publicações e com um sobressalto de 6 para 11 publicações, entre 2015 e 2016; Por fim, em 2017 manteve o mesmo índice de publicações. Ademais, percebe-se que as publicações são recentes, visto que foram publicadas nos últimos cinco anos, identificando assim que as pesquisas são crescentes sobre o tema.

$\mathrm{Na}$ Figura 3 são apresentadas as principais áreas do conhecimento que publicaram sobre empreendedorismo rural.

Figura 3- Principais áreas de publicação dos artigos.

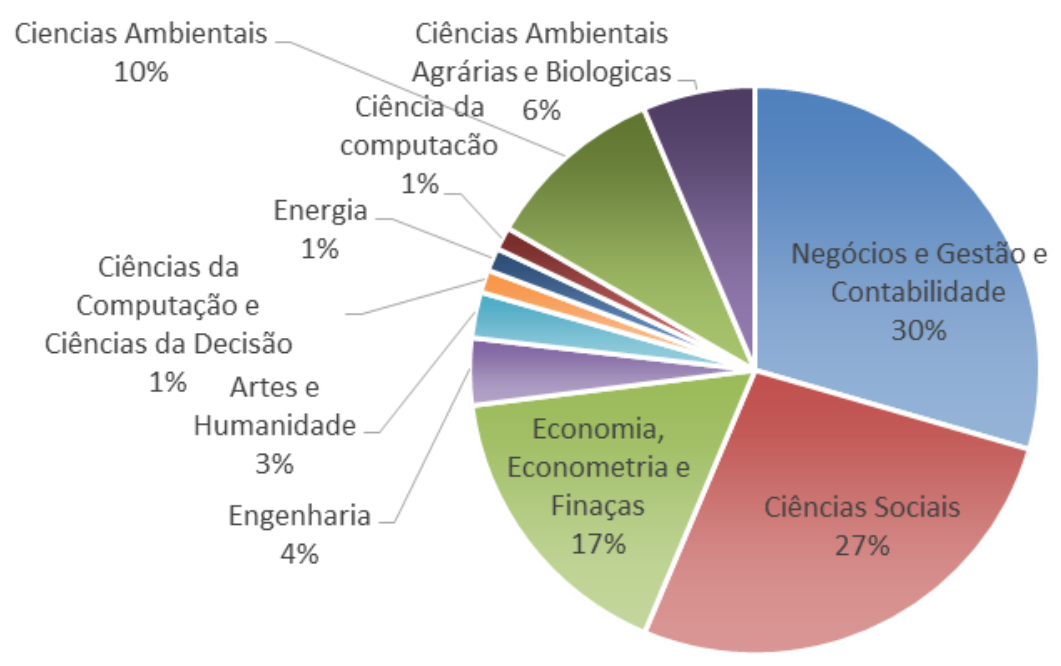

Fonte: Elaborado pelos autores (2018). 
A figura 3 permite concluir que a área específica mais evidente foi Negócios, Gestão e Contabilidade que possui (30\%) dos artigos publicados; seguida da área das Ciências Sociais com (27\%); Economia, Econometria e Finanças (17\%); Ciências Ambientais (10\%); Ciências Agrárias e Biológicas (6\%); Engenharia (4\%); Artes e Humanidade (3\%); Ciências da Computação e Ciências da Decisão (1\%). A maioria das publicações de artigos nas revistas Negócios, Gestão e Contabilidade; Ciências Sociais; Economia, Econometria e Finanças, se justifica pelo fato de o Empreendedorismo Rural ser um negócio de familiar que está inserido no meio rural, contudo, não deixando de ser uma empresa.

Além disso, é perceptível por meio dos dados obtidos que há uma grande diversidade de áreas temáticas de pesquisa, enriquecendo assim o tema Empreendedorismo Rural. Visto que, alguns estudos são classificados em mais de uma área do conhecimento, confirmando a relação de multidisciplinaridade nas pesquisas diante das temáticas. Outrossim, foram identificados os países com maior número de publicações, sobre empreendedorismo, conforme a Figura 4.

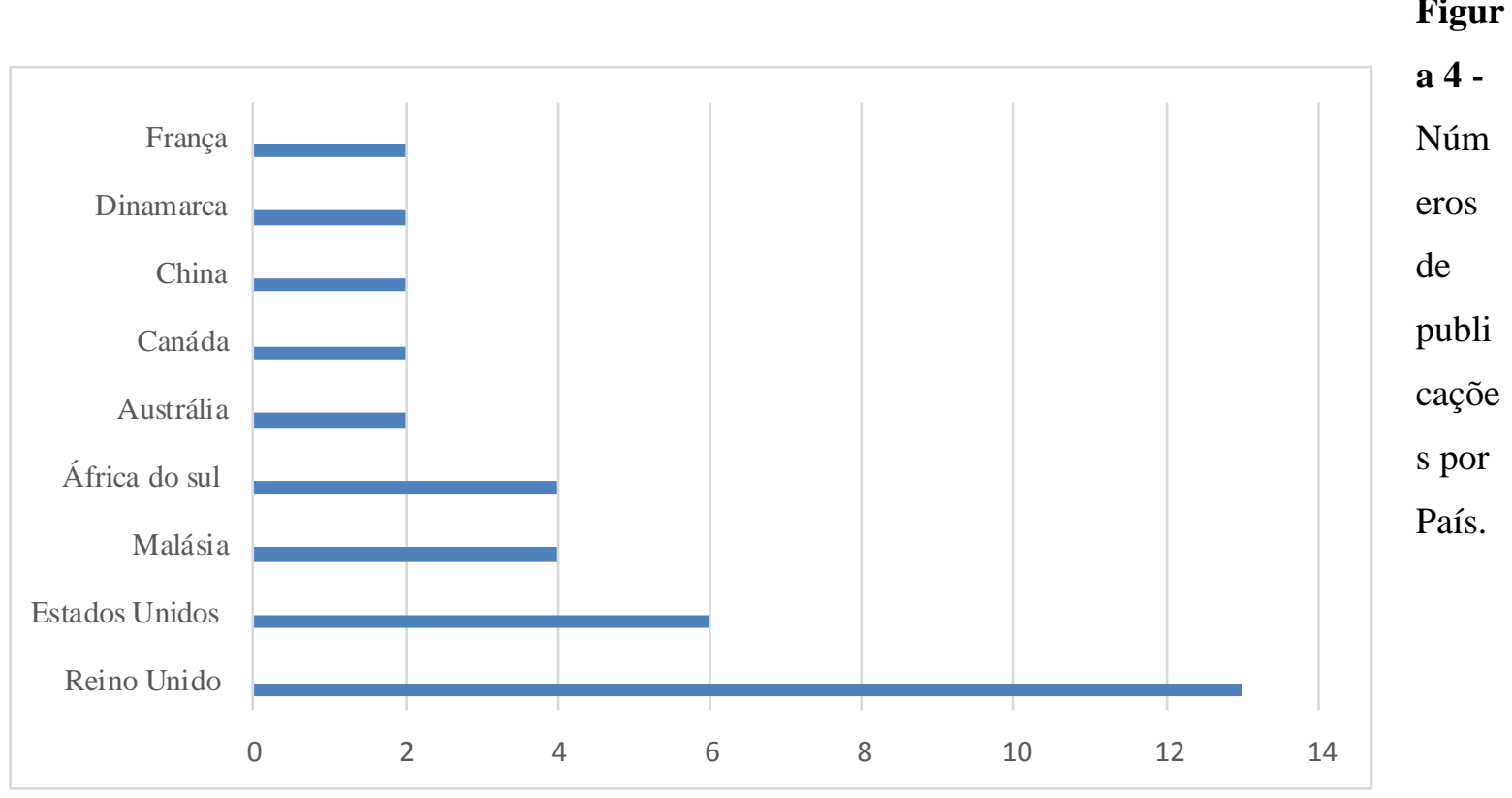

Fonte: Elaborado pelos autores (2018).

Considerando o número de publicações que abordam o tema Empreendedorismo Rural. Constatouse que o Reino Unido lidera o ranking com 13 publicações, seguido do Estados Unidos com 6, Malásia e África do Sul com 4, e por fim Austrália, Canadá, China, Dinamarca e França com 2 publicações. À vista disso pode-se explicar o destaque destes países pelo fato que neles se encontram as instituições que possuem pesquisas relacionadas com a temática, rural entrepreneurship, e também porque nos últimos anos houve significativas mudanças nas áreas rurais da União Europeia (UE). Mudanças estas ocorridas por meio das políticas agrícolas e dos fundos estruturais (PATO TEIXEIRA, 2016).

A coincidência de artigos em diferentes áreas do conhecimento ratifica a interdisciplinaridade nos estudos sobre empreendedorismo rural. A interdisciplinaridade é o encontro de diferentes disciplinas, seja no ponto de vista pedagógico ou epistemológica, para a construção de um novo conhecimento (BISPO et al., 2014).

Após identificar os países com maior número de publicações, observam-se na Figura 4, as instituições que mais publicam sobre empreendedorismo rural. 
Figura 4 -Instituições que publicaram sobre empreendedorismo rural.



Fonte: Elaborado pelos autores (2018).

As instituições que mais publicaram sobre a temática empreendedorismo rural foi a Universiti Teknologi Malaysia com 3 estudos, seguida pelas demais instituições com 2 artigos cada. No Quadro1, é realizada a revisão sistemática dos 50 artigos.

Quadro 1- Revisão Sistemática dos 50 artigos.

\begin{tabular}{|c|c|c|c|}
\hline Anos & $\begin{array}{l}\text { Quantidade } \\
\text { de Artigos }\end{array}$ & Abordagens Teóricas & Procedimentos Metodológicos \\
\hline $\begin{array}{l}2010 \text { a } \\
2017\end{array}$ & 50 artigos & $\begin{array}{l}\text { A maior parte dos artigos abordaram } \\
\text { teorias como: comportamento } \\
\text { empreendedor, de forma a investigar os } \\
\text { traços de personalidade e sua capacidade } \\
\text { de lidar com a comercialização de seus } \\
\text { negócios, fatores que influenciam seu } \\
\text { ambiente e tomada de decisão, como o } \\
\text { empreendedorismo rural reflete no } \\
\text { ambiente em que estão inseridos. } \\
\text { Buscaram examinar as correlações de } \\
\text { empreendedores bem-sucedidos em áreas } \\
\text { rurais. } \\
\text { Abordam também o desenvolvimento } \\
\text { econômico sustentável. } \\
\text { A maioria dos artigos buscaram analisar } \\
\text { as competências empreendedoras em } \\
\text { termos de empreendedorismo rural e } \\
\text { inovação. } \\
\text { Analisam o processo empreendedor no } \\
\text { qual fazem relação de oportunidades } \\
\text { empreendedoras às descobertas de } \\
\text { oportunidades empresariais. Analisam } \\
\text { estratégias de desenvolvimento dos } \\
\text { negócios e de diversificação rural, e de } \\
\text { como explorar o envolvimento dos } \\
\text { jovens rurais no empreendedorismo rural }\end{array}$ & $\begin{array}{l}\text { Os artigos possuem um número } \\
\text { significativo de estudo de caso e } \\
\text { estudos de caso múltiplos, } \\
\text { qualitativos, quantitativos, revisão } \\
\text { bibliométrica, análise comparativa e } \\
\text { sistemática. } \\
\text { Tendo como perfil de amostras, } \\
\text { micro pequenas e médias empresas } \\
\text { rurais de prestação de serviços e } \\
\text { agroindústrias de pequeno porte que } \\
\text { estão inseridas em ambientes locais e } \\
\text { regionais. }\end{array}$ \\
\hline
\end{tabular}

Fonte: Elaborado pelos autores (2018). 
Pode-se perceber por meio da análise sistemática dos artigos, que possuem uma estrutura nos quais, no resumo, foram possíveis identificar o objetivo da pesquisa, metodologia adotada, público-alvo, quantidades de respondentes e conclusões. Ademais, na própria introdução do artigo é abordado os conceitos ou teoria que norteiam a pesquisa, dispensando assim uma revisão literária dos estudos. Através dos resultados, os pesquisadores evidenciaram as principais limitações da pesquisa, e as possíveis soluções de alguns problemas e indicação de estudos futuros.

\section{CONSIDERAÇÃO FINAL}

No que se refere aos resultados apresentados, pode-se verificar que o tema é crescente na academia nos últimos anos, e diversas pesquisas tem utilizado o termo Empreendedorismo Rural. Em suma, que os achados deste estudo proporcionam contribuição acadêmica e possam servir de referência para posteriores pesquisas e para pesquisadores que venham se interessar pela temática.

Além disso, a metodologia Prisma é um instrumento importante para pesquisas sistemáticas, revelando ao pesquisador a confiabilidade de seus artigos que tratam sobre temática rural entrepreneurship. Neste estudo, em conjunto com a revisão Bibliométrica, apresenta um aparato do que tem-se publicado e ainda revela o que pode ser explorado, contribuindo assim para expansão da produção cientifica sobre a temática.

As pesquisas por mais que sejam concretizadas de maneira eficientes para busca de consolidação dos resultados acabam passando por limitações. Esta pesquisa refere-se ao universo pesquisado e os parâmetros de busca, visto que foi utilizada somente uma base de dados como fonte de pesquisa e de parâmetro de busca. Contudo, vale ressaltar a importância de devidos estudos, salientando a relevância de semelhantes pesquisas no assunto. Desta forma, sugerem-se futuros estudos que analisem a evolução da produção científica a respeito da temática rural entrepreneurship em outras bases de dados, ampliando, assim, o campo de busca.

\section{REFERÊNCIAS}

ARAÚJO, C. A. Bibliometria: evolução histórica e questões atuais. Revista em Questão, Porto Alegre, v.12, n. 1, p. 11-13, 2006.

BALRAJ, K.P; VELMURUGAN, R. Problems of rural entrepreneurship in the central districts of Tamilnadu. Journal of Advanced Research in Dynamical and Control Systems V. 2017, P. 39-44. 2017.

BRACHT, D. E., e N. B. WERLANG. "Competências empreendedoras: uma investigação com produtores rurais catarinenses." Revista do Empreendedorismo e Gestão de Pequenas Empresas v. 4, n.1, p. 101$124,2015$.

BISPO, Emanuella Pinheiro de Farias et al. Interdisciplinaridade no ensino em saúde: o olhar do preceptor na Saúde da Família. Interface - Comunicação, Saúde, Educação, [s. 1.], v. 18, n. 49, p. 337-350, 2014.

CHUN, N. M. WATANABE. Can skill diversification improve welfare in rural areas? Evidence from Bhutan. Journal of Development Effectiveness. v.4, n.2, p. 214-234, 2012. 
DE LOS RÍOS-C, I.et al. Private-Public Partnership as a tool to promote entrepreneurship for sustainable development: WWP torrearte experience. Sustainability (Switzerland), v.8, n. 3, p.199, 2016.

ESCHKER, E. et al. Rural entrepreneurs: what are the best indicators of their success? Journal of Small Business and Enterprise Development, v. 24 Issue: 2, p.278-296, 2017.

MOHER, D. et al. Principais itens para relatar revisões sistemáticas e meta-análises: a recomendação Prisma. Epidemiologia e Serviços de Saúde, v. 24, 2015.

MUHAMMAD, N,.et al. Barriers to the development and progress of entrepreneurship in rural Pakistan International Journal of Entrepreneurial Behaviour and Research v. 23, n. 2, p. 279-295, 2017.

PATO, L.TEXEIRA, A.C. Rural entrepreneurship: the tale of a rare event, Journal of Place Management and Development, v. 11, n:1, p.46-59, 2016 a.

PATO, M.L., TEIXEIRA, A.A.C.Twenty Years of Rural Entrepreneurship: A Bibliometric Survey. Sociologia Ruralis. v. 56 n.1, p. 3-28, 2016 b.

SOUTO, A. J. P., R. C. DALONGARO, S. C. NAIMER, L. U. SUDATI, e I. I. PERDONÁ. A perspectiva neoendógina no empreendedorismo rural em São Borja/RS. Revista de Empreendedorismo, Inovação e Tecnologia. vol. 2, $n^{\circ} 1$, p. 55-65, 2015.

SOUZA, P. A. R.; ANDRADE, F. A. V. MAIA, J. O. O.; REIS, P. J. N.. A agricultura familiar e a geração de renda na Amazônia: uma abordagem empreendedora no município de Parintins AM. Revista Interdisciplinar Científica Aplicada, v. 7, n. 3, p. 01-17, 2013.

TOMEI, P. A; SOUZA, D. A. A. Análise das barreiras que dificultam a transformação do agricultor familiar em empreendedor rural no contexto brasileiro. Revista Ibero-Americana de Estratégia - RIAE, v.13.n 3, 2014.

VEIGA, José Eli da. O Brasil rural ainda não encontrou seu eixo de desenvolvimento. Estud. av., São Paulo, v. 15, n. 43, p. 101-119, Dec. 2001. Disponível em

<http://www.scielo.br/scielo.php?script=sci_arttext\&pid=S010340142001000300010\&lng=en\&nrm=iso>. Acesso a 22 Ajul. 2018.

YOUNG, N.Business networks, collaboration and embeddedness in local and extra-local spaces: The case of port hardy, Canada. Sociologia Ruralis V. 50, n. 4, p. 392-408, 2010. 